\title{
Multilevel control of glucose homeostasis by adenylyl cyclase 8
}

\author{
Matthieu Raoux • Pierre Vacher • Julien Papin • Alexandre Picard • \\ Elzbieta Kostrzewa • Anne Devin • Julien Gaitan • Isabelle Limon • \\ Martien J. Kas • Christophe Magnan • Jochen Lang
}

Received: 5 September 2014 / Accepted: 28 October 2014 / Published online: 19 November 2014

(C) Springer-Verlag Berlin Heidelberg 2014

\begin{abstract}
Aims/hypothesis Nutrient homeostasis requires integration of signals generated by glucose metabolism and hormones. Expression of the calcium-stimulated adenylyl cyclase ADCY8 is regulated by glucose and the enzyme is capable of integrating signals from multiple pathways. It may thus have an important role in glucose-induced signalling and glucose homeostasis.

Methods We used pharmacological and genetic approaches in beta cells to determine secretion and calcium metabolism. Furthermore, $A d c y 8$ knockout mice were characterised.

Results In clonal beta cells, inhibitors of adenylyl cyclases or their downstream targets reduced the glucose-induced increase in cytosolic calcium and insulin secretion. This was reproduced by knock-down of ADCY8, but not of ADCY1. These agents also inhibited glucose-induced increase in cytosolic calcium and electrical activity in primary beta cells and similar effects were observed after ADCY8 knock-down.
\end{abstract}

Electronic supplementary material The online version of this article (doi:10.1007/s00125-014-3445-z) contains peer-reviewed but unedited supplementary material, which is available to authorised users.

M. Raoux · J. Papin · J. Gaitan · J. Lang $(\bowtie)$

Université de Bordeaux, CNRS UMR 5248,

Chimie et Biologie des Membranes et Nano-objets,

Batiment B14, Allée Geoffrey St Hilaire, CS90063,

F-33615 Pessac, France

e-mail: jochen.lang@u-bordeaux1.fr

M. Raoux $\cdot$ P. Vacher $\cdot$ A. Devin $\cdot$ J. Gaitan $\cdot$ J. Lang

Université de Bordeaux, Bordeaux, France

P. Vacher

Inserm Unité U 916, Institut Bergonié,

Bordeaux, France

A. Picard $\cdot$ C. Magnan

BFA-Unité de Biologie Fonctionnelle et Adaptative-UMR CNRS

8251, Université Paris-Diderot, Paris, France
Moreover, insulin secretion was diminished in islets from Adcy 8 knockout mice. These mice were glucose intolerant after oral or intraperitoneal administration of glucose whereas their levels of glucagon-like peptide-1 remained unaltered. Finally, we knocked down ADCY8 in the ventromedial hypothalamus to evaluate the need for ADCY8 in the central regulation of glucose homeostasis. Whereas mice fed a standard diet had normal glucose levels, high-fat diet exacerbated glucose intolerance and knock-down mice were incapable of raising their plasma insulin levels. Finally we confirmed that ADCY8 is expressed in human islets.

Conclusions/interpretations Collectively, our findings demonstrate that ADCY8 is required for the physiological activation of glucose-induced signalling pathways in beta cells, for glucose tolerance and for hypothalamic adaptation to a high-fat diet via regulation of islet insulin secretion.

\author{
E. Kostrzewa $\cdot$ M. J. Kas \\ Department of Translational Neuroscience, Brain Center Rudolf \\ Magnus, University Medical Centre Utrecht, \\ Utrecht, the Netherlands \\ A. Devin \\ Institut de Biochimie et Génétique Cellulaires, UMR CNRS 5095, \\ Bordeaux, France \\ I. Limon \\ Université Pierre et Marie Curie, UR4 Aging, Stress and \\ Inflammation, Paris, France \\ Present address: \\ J. Papin \\ Laboratoire de Pharmacodynamie et de Thérapeutique, Faculté de \\ Médecine, Université Libre de Bruxelles, Bruxelles, Belgium
}


Keywords Adenylyl cyclase · Diabetes · Glucose

homeostasis · Insulin secretion · Intracellular calcium $\cdot$ Islets of

Langerhans

$\begin{array}{ll}\text { Abbreviations } \\ \text { AAV } & \text { Adeno-associated virus } \\ \text { ADCY } & \text { Adenylyl cyclase } \\ {\left[\mathrm{Ca}^{2+}\right]_{i}} & \text { Free cytosolic calcium } \\ \text { CMV } & \text { Cytomegalovirus } \\ \text { EPAC } & \text { Exchange protein activated by cAMP } \\ \text { GFP } & \text { Green fluorescent protein } \\ \text { GLP-1 } & \text { Glucagon-like peptide-1 } \\ \text { HFD } & \text { High-fat diet } \\ \text { shRNA } & \text { Short hairpin RNA } \\ \text { siRNA } & \text { Short interfering RNA } \\ \text { PKA } & \text { Protein kinase A } \\ \text { VMH } & \text { Ventromedial hypothalamus }\end{array}$

\section{Introduction}

The interplay of nutrients and hormones ensures tight control of blood glucose levels and the pancreatic islets of Langerhans constitute a major player in this system [1]. In islet beta cells the metabolism of nutrients increases cytosolic calcium $\left(\left[\mathrm{Ca}^{2+}\right]_{\mathrm{i}}\right)$, which triggers insulin secretion and remodels gene expression. Glucose metabolism also induces the generation of another second messenger, cAMP, via adenylyl cyclases [2]. Postprandial hormones, such as glucagon-like peptide-1 (GLP-1), considerably enhance the effect of nutrient metabolism on the cAMP pathway. cAMP activates downstream effectors, protein kinase A and the guanine nucleotide exchange factor EPAC (exchange protein activated by cAMP), which regulate insulin secretion and potentiate the effects of calcium [3, 4]. A further level of integration is provided by the control of beta cells via neuronal input [5].

Dysfunctional secretion of insulin contributes to type 2 diabetes and prolonged exposure of islet cells to hyperglycaemia may alter the system [1]. We have previously observed that a beta cell-specific subtype of adenylyl cyclases, adenylyl cyclase (ADCY) 8, was among the most strongly downregulated transcripts and proteins in rat and human islets exposed to elevated glucose concentrations [6]. The $\mathrm{Ca}^{2+}$ sensitive ADCY8 may serve as a coincidence detector as it senses glucose via increasing $\left[\mathrm{Ca}^{2+}\right]_{\mathrm{i}}$ and incretins through Gprotein coupled receptors [6-8]. Similar to ADCY8, ADCY1 is also stimulated by $\mathrm{Ca}^{2+}[8]$ whereas ADCY5 and ADCY6 are inhibited by the cation $[9,10]$. ADCY 8 is also expressed in brain regions that participate in the control of energy homeostasis and nutrition (i.e. the hypothalamus) [11]. Moreover, genetic data hint at a potential role for ADCY8 in nutrient homeostasis in rodents [12-14]. To obtain insight into the role of ADCY8, we therefore investigated its function at the cellular and whole-body level.

\section{Methods}

Materials All drugs were from Sigma (Saint-Quentin, France). Anti-ADCY1 and anti-ADCY 8 antibodies were from Santa Cruz Biotechnology (Santa Cruz, CA, USA). Plasmids encoding short hairpin RNA (shRNA) were from SABiosciences (Frederick, MD, USA); plasmids encoding ADCY8 were as described [6].

Plasmids and oligonucleotides BIOPREDsi (www.biopredsi. org) and Invitrogen (Life Technologies SAS, Saint Aubin, France) bioinformatics tools were used to identify possible short interfering RNA (siRNA)/shRNA sequences against the mouse Adcy 8 gene. Four sets of two oligonucleotides (Stratagene, Amsterdam, the Netherlands) with SapI and Xbal overhangs were used, a set of shRNA oligonucleotides against the Renilla gene served as a control (control shRNA).

Annealed oligonucleotides were ligated into SapI-/XbaIdigested pAAV-sHbAse containing a mouse U6 promoter, a terminator sequence following the shRNA sequence and expressing green fluorescent protein (GFP) under a cytomegalovirus (CMV) promoter hybridised to a $\beta$-actin intron followed by an independent terminator sequence. Mouse Adcy 8 cDNA was cloned into p3xflag-Renilla kindly provided by M. Vooijs, (UMC Utrecht, the Netherlands) to obtain the ADCY 8-Renilla fusion plasmid. pcDNA4/TO-luc (luciferase) was a kind gift from M. van der Wetering (UMC Utrecht, the Netherlands). All constructs were confirmed by sequencing.

Quantitative PCR Quantitative PCR was performed as described previously [6]. Primers used in human tissues (see electronic supplementary material [ESM] List of primers) were validated first on human post-mortem brain frontal cortices as at least in rodents they are known to express high levels of ADCY8 [15].

Virus production and purification Production of adenoassociated virus (AAV) was performed on $15 \times 15 \mathrm{~cm}$ dishes of $293 \mathrm{~T}$ cells at $80-90 \%$ confluency on the day of transfection. Two hours before transfection, 10\% FCS-DMEM was replaced with $2 \%$ FCS-DMEM. Transfections were performed with polyethylenimine as published [16] and pAAV-CMV-GFP was co-transfected with helper plasmid pDP1 in a molar ratio of 1:1. Cells were incubated with transfection mix until the following day. Virus production and purification was performed as described [17] and detailed in ESM Methods. 
Animals and cells Progeny of C57BL/6 Adcy8 ${ }^{-/-}[18]$ and wild-type mice were bred in our colony except for pharmacological experiments using calcium microfluorometry where NMRI mice were employed (Charles River, Chatillon-surChalaronne, France). Wild-type C57BL/6 mice born on similar dates as $A d c y 8^{-/-}$mutant litters were used as controls. All experimental procedures were approved by the Ministry of Education and Research (no. 01836.01). Mice were genotyped by PCR (see ESM List of primers). Mouse and human islets were obtained and cultured as described $[6,19]$. INS832-13 and MIN6 cells were generously provided by C. Newgaard (Duke University, Durham, NC, USA) and J. Miyazaki (Osaka University, Osaka, Japan).

Stereotaxic injections and follow-up Isoflurane-anaesthetised mice were injected bilaterally with genomic particles of AAV in the ventromedial hypothalamus (VMH) over $10 \mathrm{~min}$ per side ( $n=6 /$ group). The volume of the injection was $0.3 \mu \mathrm{l}$, given at a rate of $0.1 \mu \mathrm{l} / \mathrm{min}$. At the bregma and lambda level, coordinates were as follows: $1.64 \mathrm{~mm}$ caudal to bregma, $0.5 \mathrm{~mm}$ lateral to midline, $5.9 \mathrm{~mm}$ below dura. Mice injected with AAV-anti-ADCY8 or AAV-scrambled were fed either regular chow diet or high-fat diet (HFD) (40\% lipids, HF235; Safe, Toulouse, France). OGTT and ITT were performed 8 weeks after AAV injection.

Glucose and insulin tolerance tests, islet secretion assays and morphometric analysis Glucose and insulin tolerance tests were performed as described [19]. Islets were cultured overnight in CMRL-1066 (Invitrogen, Life Technologies SAS, Saint Aubin, France) supplemented with $0.25 \%$ human serum albumin, $20 \mathrm{mmol} / 1 \mathrm{~L}$-glutamine, $64 \mathrm{mg} / \mathrm{l}$ gentamicin and $25 \mathrm{mmol} / 1 \mathrm{HEPES}$ at $37^{\circ} \mathrm{C}$ in $95 \% \mathrm{O}_{2} / 5 \% \mathrm{CO}_{2}$ and saturated humidity in 96-well filter plates (multiscreen Durapore BV1.2 $\mu \mathrm{m}$; Millipore, Molsheim, France). Static insulin release was assayed as published [20]. Pancreatic beta cell mass was measured on deparaffinised, rehydrated pancreas sections immunostained for insulin and counterstained with haematoxylin [20].

Microfluorometry, electrophysiology, insulin secretion, immunofluorescence and measurement of oxygen consumption Cell culture, transfections, immunofluorescent staining, measurement of $\left[\mathrm{Ca}^{2+}\right]_{\mathrm{i}}$ and secretion assays were performed as reported $[6,21]$. For calcium imaging in mouse islets, the islets were seeded on glass coverslips coated with poly-D-lysine/ laminin (30-50 dissociated islets/coverslip, $25 \mathrm{~mm}$ diameter) and transfected after 2-24 h with lipofectamine for $24 \mathrm{~h}$. Electrophysiological recordings were performed according to published methods [21, 22]. Oxygen consumption was measured polarographically at $37^{\circ} \mathrm{C}$ by high-resolution respirometry with an-OROBOROS Oxygraph-2k (OROBOROS Instruments, Innsbruck, Austria) using 1.5-3 million cells in
KRB (in mmol/l: $\mathrm{NaCl} 135, \mathrm{KCl} 4.8, \mathrm{MgCl}_{2} 1.2, \mathrm{CaCl}_{2} 2.5$, HEPES 10, glucose as indicated, $\mathrm{pH} 7.4$ adjusted with $\mathrm{NaOH}$ ). Active GLP-1 was measured with an ELISA kit (Millipore, Watford, UK).

Statistics Values are expressed as mean \pm SEM. Comparison of means was made either by Student's $t$ test or by one-way ANOVA followed by post hoc tests.

\section{Results}

ADCY8 is required for glucose-evoked increases in cytosolic calcium and insulin secretion We first asked whether adenylyl cyclase activity is required for glucose-induced $\left[\mathrm{Ca}^{2+}\right]_{\mathrm{i}}$ responses in beta cells. Stimulation by $15 \mathrm{mmol} / 1$ glucose or $25 \mathrm{mmol} / \mathrm{l} \mathrm{KCl}$ increased free $\left[\mathrm{Ca}^{2+}\right]_{\mathrm{i}}$ in clonal INS-1E beta cells (Fig. 1a, b). Pre-incubation with the cAMP antagonist Rp-cAMPS, protein kinase A (PKA) inhibitor H-89 or the general adenylyl cyclase blocker SQ22,356 largely reduced the effect of glucose (Fig. 1c, e-g). Notably, this was not the case when cells were depolarised by $\mathrm{KCl}$ (Fig. 1d, g). The glucose-evoked rise in $\left[\mathrm{Ca}^{2+}\right]_{\mathrm{i}}$ was also reduced to $33 \%$ by Rp-cAMPS in the subclone INS $832 / 13$ (not shown). Forskolin enhanced glucose-induced insulin secretion (Fig. 1h). The inhibitors used did not change basal insulin release at $2 \mathrm{mmol} / \mathrm{l}$ glucose but they reduced the insulin secretion evoked by $15 \mathrm{mmol} / \mathrm{l}$ glucose and also counteracted the effect of forskolin. These data indicate that adenylyl cyclase activity is required for glucose-induced increases in $\left[\mathrm{Ca}^{2+}\right]_{\mathrm{i}}$ and insulin secretion in clonal beta cells.

To test whether this adenylyl cyclase activity encompasses ADCY8, the enzyme was knocked down as published [6]. This induced a large reduction in the $\left[\mathrm{Ca}^{2+}\right]_{\mathrm{i}}$ response to glucose (Fig. 2a) whereas $\mathrm{KCl}$ - or thapsigargin-induced increases in $\left[\mathrm{Ca}^{2+}\right]_{i}$ remained unchanged. We also tested INS832/13 cells [23] (Fig. 2b, c). Again, knock-down of ADCY8 largely reduced the effect of glucose on $\left[\mathrm{Ca}^{2+}\right]_{\mathrm{i}}$ and overexpression of $\mathrm{ADCY} 8$ led to a fivefold increase in glucose-induced increases in $\left[\mathrm{Ca}^{2+}\right]_{\mathrm{i}}$ (Fig. 2c). Knock-down of ADCY1 only increased the effect of glucose despite a reduction in ADCY1 protein levels (see ESM Fig. 1). Knock-down of ADCY8 reduced glucose-stimulated insulin secretion by more than $80 \%$ and led to some reduction in $\mathrm{KCl}-$ evoked secretion, whereas knock-down of ADCY1 resulted only in minor changes (Fig. 2d). As adenylyl cyclases have been implicated in the regulation of mitochondrial metabolism [24], we also investigated the effect of ADCY8 on oxygen consumption in INS-1E cells. Although an effect of adenylyl cyclase was evident, this did not concern the isoform ADCY8 (ESM Fig. 2). 
a

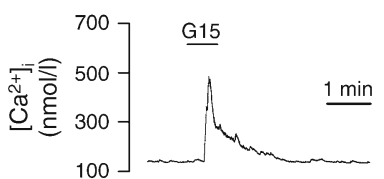

C

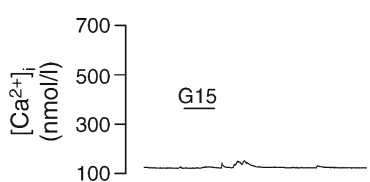

e

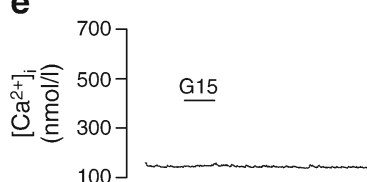

f

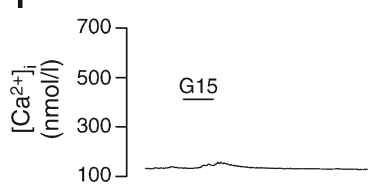

b

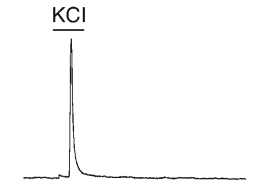

d

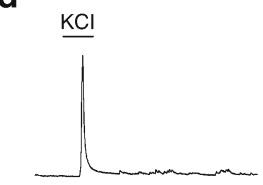

g

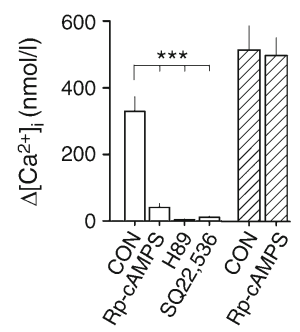

a

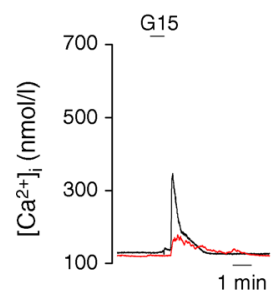

b

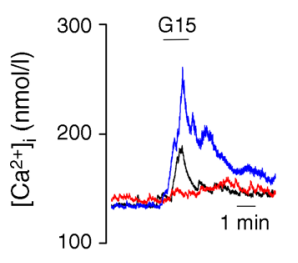

C

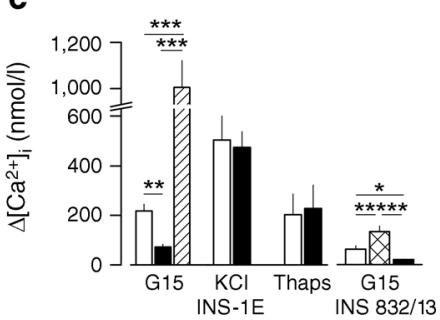

d

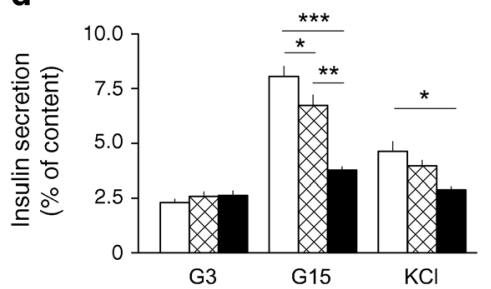

Fig. 2 ADCY8 is required for glucose-induced changes in $\left[\mathrm{Ca}^{2+}\right]_{i}$ and in insulin secretion in clonal beta cells. $(\mathbf{a}-\mathbf{c})$ Clonal INS-1E $(\mathbf{a}, \mathbf{c})$ or INS832/13 (b, c) cells were transiently co-transfected with a plasmid encoding DsRED and a control shRNA (black traces; white bars) or shRNAs against ADCY1 (blue traces, cross-hatched bars) or ADCY8 (red traces, filled bars) or with a plasmid encoding ADCY8 (hatched bar). Three days later, cells were exposed to $15 \mathrm{mmol} / \mathrm{l}$ glucose (G15), $25 \mathrm{mmol} / 1 \mathrm{KCl}$ or $100 \mathrm{nmol} / 1$ thapsigargin (Thaps). $n=3-50 ; * p<0.05$, $* * p<0.01$ and $* * * p<0.001$ (Newman-Keuls post hoc test) for the indicated comparisons. (d) INS832/13 cells were transiently co-transfected with a plasmid encoding human growth hormone and a plasmid encoding a control shRNA (white bars) or shRNAs directed against ADCY1 (cross-hatched bars) or ADCY8 (black bars). Three days later, cells were exposed to $3 \mathrm{mmol} / \mathrm{l}$ glucose (G3), $15 \mathrm{mmol} / \mathrm{l}$ glucose (G15) or $35 \mathrm{mmol} / \mathrm{l}$ KCl. $n=6-12 ; * p<0.05,{ }^{* *} p<0.01$ and ${ }^{* * *} p<0.001$ (Tukey's post hoc test) for the indicated comparisons

cytosol. Glucose-induced electrical oscillations were reversibly suppressed by protein kinase A-inhibitor H-89 and inhibited by pre-incubation with adenylyl cyclase blocker MDL 12330 (Fig. 3d, e). The inhibition by H-89 was also observed in INS1-E cells (data not shown).

To investigate whether ADCY8 is involved in the observed pharmacological inhibition of glucose-induced changes in $\left[\mathrm{Ca}^{2+}\right]_{\mathrm{i}}$, we resorted again to its knock-down in primary cells. This largely reduced the response of $\left[\mathrm{Ca}^{2+}\right]_{\mathrm{i}}$ to glucose but not to $\mathrm{KCl}$ (Fig. 4), similar to the observations made in clonal cells. The knock-down could be partially rescued by the addition of the cell-permeable cAMP analogue 8-Br-c-AMP, demonstrating the specificity of the procedure. To evaluate the potential role of ADCY 8 in insulin secretion, we tested islets from $A d c y 8$ knockout mice. Note that only $A d c y 8$ was 

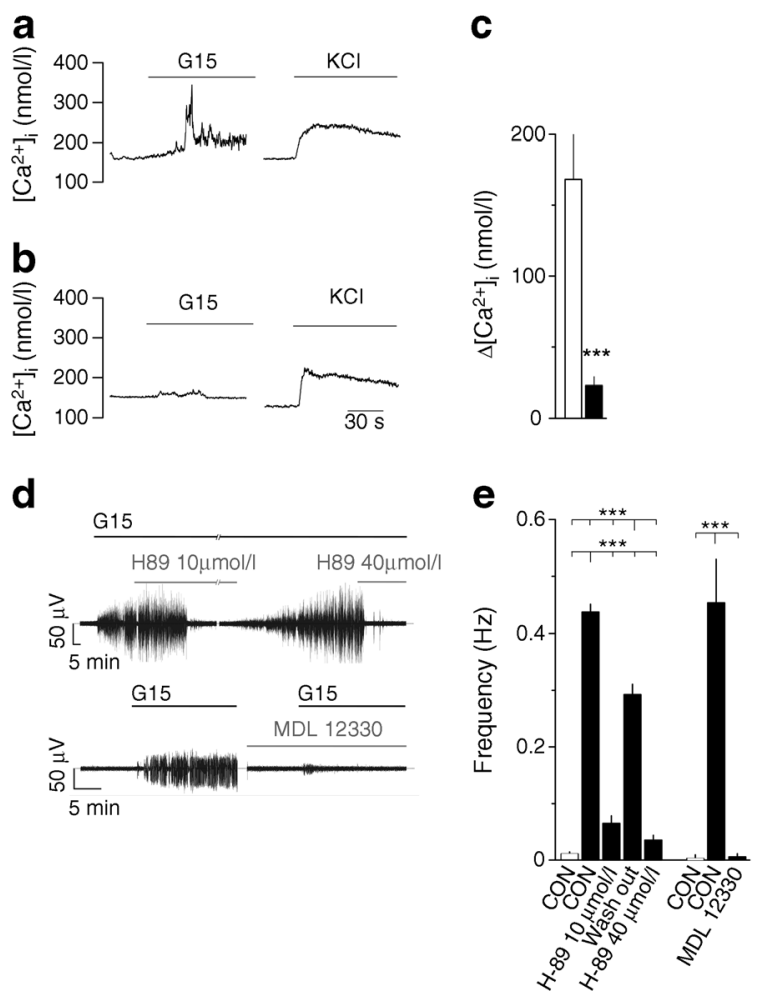

Fig. 3 Inhibitors of adenylyl cyclases or protein kinase A reduce glucose-induced changes in $\left[\mathrm{Ca}^{2+}\right]_{i}$ and electrical activity in primary beta cells. (a-c) Cells were pre-incubated in the absence (a, white bar in $\mathbf{c})$ or presence of $50 \mu \mathrm{mol} / 1 \mathrm{Rp}$-cAMPS (b, black bar in $\mathbf{c}$ ) and subsequently stimulated by glucose $(15 \mathrm{mmol} / \mathrm{l}, \mathrm{G} 15)$ or $\mathrm{KCl}(25 \mathrm{mmol} / \mathrm{l}, \mathrm{KCl}) . n=43-$ 49; $* * * p<0.001$ (unpaired $t$ test) vs no Rp-cAMPS. (d) Representative traces from extracellular electrical recordings of islets cells on multielectrode arrays. Cells were recorded at $3 \mathrm{mmol} / \mathrm{l}$ glucose (G3) and stimulated with $15 \mathrm{mmol} / \mathrm{l}$ glucose (G15) in the absence or presence of $\mathrm{H}-89$ ( $10 \mu \mathrm{mol} / 1$ initial exposure and $40 \mu \mathrm{mol} / 1$ after wash-out) or MDL12330 (10 $\mu \mathrm{mol} / \mathrm{l})$. (e) Statistics of experiments, as for (d), at G3 (white bars) or at $\mathrm{G} 15$ without $(\mathrm{CON})$ or with indicated drugs (black bars). $n=37-45 ; * * * p<0.001$ (Tukey's post hoc test) for the indicated comparisons vs $\mathrm{CON}$ or vs wash-out

undetectable in the islets of knockout mice, whereas Adcyl, Adcy5 and Adcy6 remained unchanged (ESM Table 1). Increasing the glucose concentration from $5.5 \mathrm{mmol} / 1$ to $16.7 \mathrm{mmol} / \mathrm{l}$ induced a twofold increase in insulin secretion (Fig. 5); this increase was reduced by $50 \%$ in the Adcy 8 knockout mice. In contrast, beta cell masses did not significantly differ.

ADCY8 regulates glucose tolerance in vivo Our analysis at the cellular and organ level indicated that ADCY8 is required for glucose-induced responses. Therefore we asked whether ADCY 8 may also be involved in nutrient homeostasis in the whole animal. $A d c y 8^{-/-}$mice were lean and did not exhibit any prominent phenotype. As shown in Fig. 6a, b, knockout mice were glucose intolerant during an OGTT whereas their insulin tolerance remained unchanged, indicating a normal sensitivity to the hormone (Fig. 6c). We did not observe any difference in active plasma GLP-1 concentration during
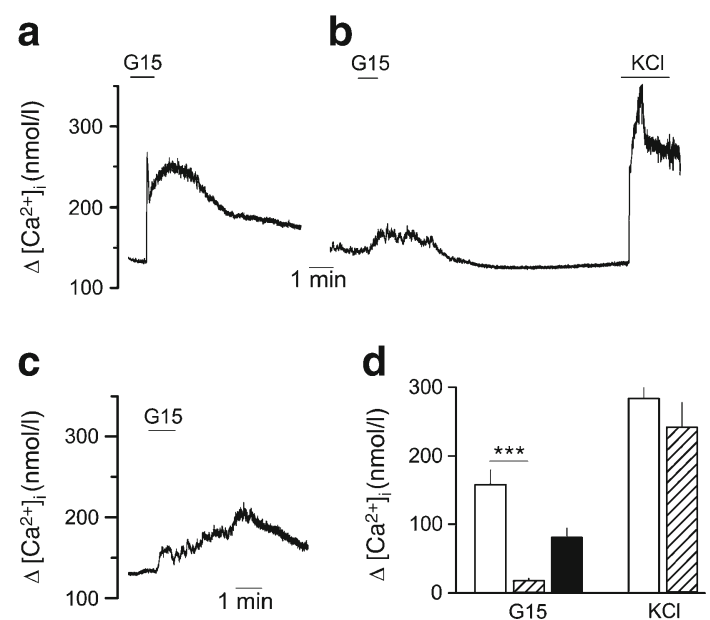

Fig. 4 Knock-down of ADCY8 reduces glucose-induced increases in $\left[\mathrm{Ca}^{2+}\right]_{\mathrm{i}}$ in primary beta cells. Primary cells were co-transfected with plasmids encoding control shRNA (a) or directed against ADCY8 (b, c) and stimulated by $25 \mathrm{mmol} / 1 \mathrm{KCl}(\mathrm{KCl})$ or by $15 \mathrm{mmol} / 1$ glucose (G15) in the absence $(\mathbf{a}, \mathbf{b})$ or presence of $1 \mathrm{mmol} / \mathrm{l}$ 8-Br-cAMP $(\mathbf{c})$. $(\mathbf{a}-\mathbf{c})$ show representative traces and (d) shows the statistics. White bars, control shRNA; hatched bars, shADCY8; black bars, shADCY8 with addition of 8-Br-cAMP. $n=6-46$; $* * * p<0.001$ (Tukey's post hoc test), control shRNA vs shADCY8

OGTT (Fig. 6d) between the two mouse groups. We also performed intraperitoneal glucose tolerance tests, which bypass the effects of incretin (Fig. 6e, f), and confirmed the glucose intolerance of $A d c y 8^{-/-}$mice.

ADCY8 is expressed in brain, including the hypothalamus [11], and may be involved in glucose homeostasis. To knockdown ADCY8, we used stereotaxic injections into the VMH of either control virus or virus encoding shRNA directed against ADCY8 (AAV shADCY8; for details see ESM Table 2). The VMH area encompasses the ventromedial hypothalamic nucleus and arcuate nucleus, which contain glucose-sensing neurons involved in glucose homeostasis [25]. Mice were kept on a normal diet for 8 weeks to recover from the procedure and subsequently maintained on either normal diet or HFD for 2 weeks. Virus injection produced no significant change in food intake or body weight compared
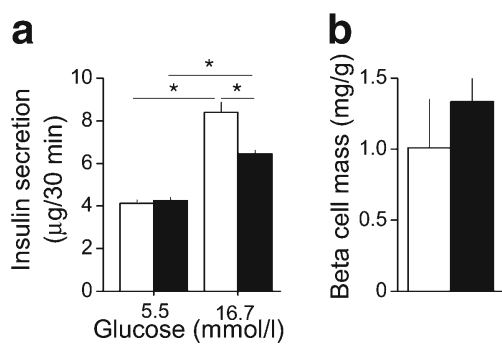

Fig. 5 Knockout of $A d c y 8$ reduces glucose-induced insulin secretion from islet beta cells. (a) Insulin release was measured from islets obtained from male $A d c y 8^{+/+}$(white bars) or $A d c y 8^{-1-}$ mice (black bars) during $30 \mathrm{~min}$ static exposure to $5.5 \mathrm{mmol} / 1$ glucose or 16.7 glucose. $n=5$; ${ }^{*} p<0.05$ (Bonferroni's post hoc test) for the indicated comparisons. (b) Beta cell mass was determined in wild-type (white bar) or knockout mice (black bars). $n=3-6$ 

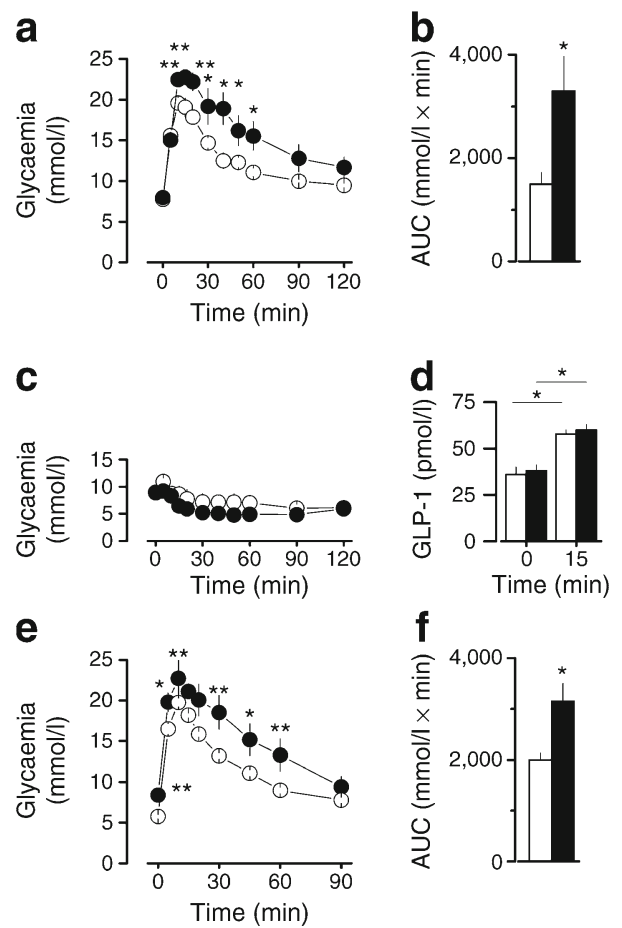

Fig. 6 Knockout of Adcy8 impairs glucose tolerance. (a-c) Male mice, either $A d c y 8^{+/+}$(white symbols and bars) or $A d c y 8^{-/-}$(black symbols and bars), were subjected to OGTT (a) (AUCs shown in b normalised to values in $A d c y 8^{+/+}$mice) and ITT (c). (d) Active plasma GLP-1 levels were measured at time 0 or 15 min after oral glucose challenge. (e, f) Results of an intraperitoneal glucose tolerance test are given in (e), with normalised AUC shown in (f). $n=5-11 ; * p<0.05$ and $* * p<0.01$ (Student-Welch test), $A d c y 8^{-/-}$mice vs $A d c y 8^{+/+}$mice or for indicated comparisons

with mice undergoing no surgery (data not shown). Postmortem assessment of the injection sites did not show mechanical damage due to the procedure or gross alteration (see ESM. Fig. 3a). AAV shADCY8 induced a $40 \%$ reduction in Adcy 8 mRNA as compared with control injections (ESM Fig. 3b). In an OGTT (Fig. 7 a, b) knock-down of ADCY8 in the $\mathrm{VMH}$ alone did not induce glucose intolerance in mice maintained on a normal diet. A 2 week period of HFD induced glucose intolerance in the control mice and this intolerance was markedly increased by knock-down of ADCY8. HFD also produced a significant increase in insulin secretion in control mice as a means of allowing them to cope with the increased load in nutrients (Fig. 7c). This increase was absent in mice after ADCY8 had been knocked down in the VMH, and hormone levels in these mice were comparable with those observed in mice kept on normal diet. In contrast, there was no difference within the HFD groups in terms of insulin sensitivity between the mice of differing VMH ADCY8 status (Fig. 7d).

Finally we re-examined whether ADCY8 is indeed expressed in human islets in view of contradictory reports [6, 26-29]. We first validated primers in human brain cortices and two primers designed in-house that amplify sequences in
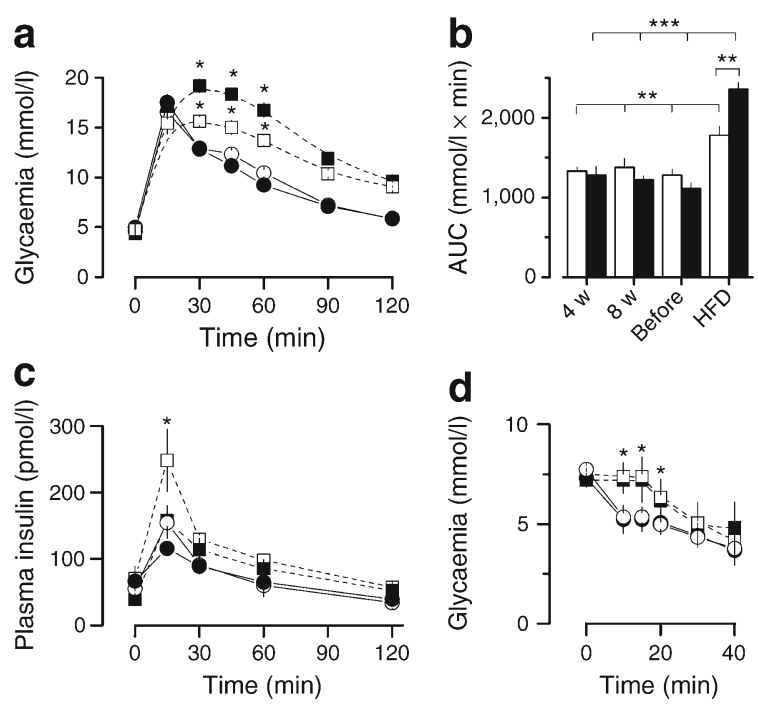

Fig. 7 Knock-down of ADCY8 in the VMH enhances glucose intolerance in mice maintained on an HFD. Male mice were injected in the $\mathrm{VMH}$ with either control AAV virus (white symbols and bars) or AAV encoding shRNA directed against ADCY8 (black symbols and bars). Mice were either maintained on a normal diet (circles) or an HFD (squares). (a) OGTT of mice at 10 weeks after injections. (b) Results of OGTTs at different time points before and after injections under normal diet (4w, 4 weeks; 8w, 8 weeks) and under subsequent HFD for 2 weeks (HFD). (c, d), Plasma insulin levels (c) and ITT (d) in the same mice as in (a) and (b). $n=3-8 ; * p<0.05 ; * * p<0.01$ and ${ }^{* * *} p<0.001$ vs HFD in control or knock-down mice (Student-Welch test in a, c, d; Tukey's test in b)

exon 9 and 10 or within exon 18, passed the control and detected ADCY 8 at $\mathrm{C}_{t}$ s between 29 and 30 . They also clearly detected $\mathrm{ADCY} 8$ in islet preparations (Fig. 8) and $\mathrm{C}_{\mathrm{t}} \mathrm{s}$ were comparable with those of succinate dehydrogenase $\mathrm{A}$ and TATA box-binding protein. Although levels were low, as expected for ADCY8 in many human organs including brain [30], the $\mathrm{C}_{t} \mathrm{~s}$ observed in cortices during the validation phase were quite similar to those measured in islets. A primer pair previously used in another study reporting the absence of ADCY8 in human islets [28] did not pass the quality control in brain samples.

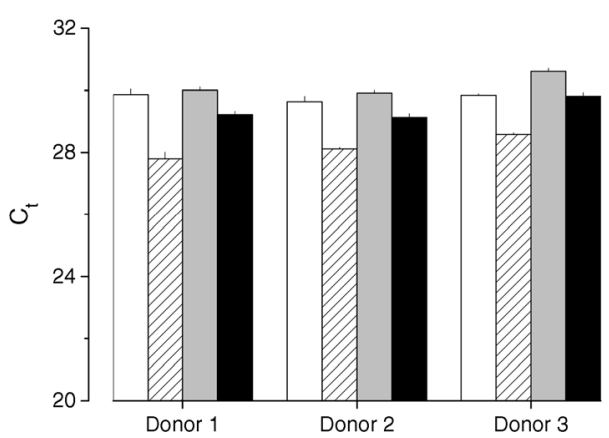

Fig. 8 ADCY 8 is expressed in human islets. $C_{t}$ s for reactions using primers specific for TATA box-binding proteins (white bars), succinate dehydrogenase A (hatched bars), or amplifying in ADCY8 exon 9 to 10 (grey bars) or exon 18 (black bars), are given for samples from three healthy donors 


\section{Discussion}

Glucose metabolism increases cAMP in beta cells and cAMP is required for the physiological secretory response [31] but detailed molecular events are still only partially understood [4]. Our data indicate that ADCY8 is not only required in beta cells for glucose responsiveness and glucose tolerance but also necessary for hypothalamic adaptation to changes in the metabolic status.

The importance of cAMP in the generation of the glucoseinduced calcium signal is supported by the observation that several agents acting at distinct levels within the PKA pathway inhibited glucose-induced increases in $\left[\mathrm{Ca}^{2+}\right]$, electrical activity and insulin secretion. The kinase inhibitor H-89 had been reported not to alter the effect of glucose in intact islets [32]. However, recent pharmacological data from mouse [2], rat [33] and human islets [28, 34] are in line with our observations. Previously reported differences may be due to the timing of drug addition as they are less evident once glucoseinduced effects are installed [2].

Calcium may regulate cAMP levels through ADCY1 or ADCY8, as both are stimulated by $\mathrm{Ca}^{2+} /$ calmodulin and are expressed in beta cells $[6,7]$. The recently reported effects of knock-down of ADCY1 in MIN6 cells also underlines a tight link between cAMP, regulation of $\left[\mathrm{Ca}^{2+}\right]_{\mathrm{i}}$ and insulin secretion [35]. We have observed an increase in $\left[\mathrm{Ca}^{2+}\right]_{\mathrm{i}}$ rather than a loss of glucose effects after knock-down of ADCY1 and have no ready explanation for this effect, which may stem from adaptation. Note also that in contrast with our study, the clone of MIN6 cells used in the ADCY1 study [35] did not express ADCY8, in contrast to INS-1E or primary beta cells $[6,7]$ (or MIN6 cells used by us, see ESM Fig. 1). ADCY8 is clearly expressed to a comparable extent in pancreatic $\beta$-cells in rodents and in humans although levels are low as reported previously [6]. Expression of ADCY8 in human islets has also been reported most recently using a primer different from ours [29] and the long-known existence of splice variants [36] may explain its reported absence in certain studies.

Our data lend further substance to the proposed role of ADCY8 as a coincidence detector integrating glucose and hormonal signals $[6,7]$. At least in rodent clonal or primary beta cells GLP-1-induced cAMP signalling is transduced via ADCY8 $[6,33]$. cAMP has mostly been regarded as an amplifier of glucose-evoked $\mathrm{Ca}^{2+}$ actions rather than a mandatory component. Our data now suggest that glucose-evoked increase in cAMP is required to obtain the expression of beta cell responses on electrical activity, $\left[\mathrm{Ca}^{2+}\right]_{\mathrm{i}}$ and insulin secretion. These effects are mediated via ADCY8, as shown here, and a recent electrophysiological analysis [33] suggested close spatial relation between ADCY8 and exocytosis. Clearly, glucose-specific effectors could be involved downstream of the enzyme. The $\mathrm{K}_{\mathrm{ATP}}$-channel is regulated by cAMP via EPAC or via PKA $[37,38]$. Interaction between ADCY8 and Orai1 [39], a component of store-operated calcium entry, probably does not play a major role [40] and knock-down of ADCY 8 did not alter thapsigargin-induced increases in $\left[\mathrm{Ca}^{2+}\right]_{\mathrm{i}}$ in our system.

In addition to ADCY8, other adenylyl cyclase isoforms are implicated in the regulation of beta cells. A soluble cytoplasmic form, sAC/ADCY10, is stimulated by calcium, may transduce metabolic changes and its knockout in mice leads to glucose intolerance [41]. More recently it has been shown that ADCY5, an $\alpha$-cell-specific enzyme in rodents inhibited by calcium [7, 9], is expressed in beta cells in humans and is required for glucose-evoked, but not for GLP-1-mediated, effects [28]. As knock-down or knockout of any of these three isoforms does not completely abolish insulin secretion, all three may be implicated, acting at distinct levels. Whereas sAC could be involved in mitochondrial generation of coupling factors, $\mathrm{ADCY} 8$ is required for sufficient increases in $\left[\mathrm{Ca}^{2+}\right]_{\mathrm{i}}$. ADCY8, moreover, acts on a late step in exocytosis, as shown by capacitance measurements $[6,33]$, its presynaptic expression in neurons [42] and the altered docking of synaptic vesicles in ADCY8 knockout mice [43].

Our observation in $A d c y 8$ knockout mice is in line with genetic data in rodents on energy homeostasis. Niddm19, a locus implicated in postprandial glucose levels in the rat, encompasses several hundred genes, including $A d c y 8$ [12]. In NZ mice, $B g l u 8$ could be reduced to 12 candidate genes, including $A d c y 8$ [13], and the locus $D b m 4$, a non-obese model for type 2 diabetes, includes $A d c y 8$ [14]. Moreover, $A D C Y 8$ is one of three main clusters involved in the domestication of dogs from wolves [44]. This observation was interpreted on the basis of altered aggressiveness, but may also reflect a difference between metabolic states in the wolf depending on prey and the dog kept on full board.

Knock-down of ADCY8 in the hypothalamus did not result in glucose intolerance but additional metabolic stress, such as HFD, revealed the requirement for ADCY8. Therefore, hypothalamic ADCY8 is required to allow adaptation to an altered metabolic environment. Most interestingly, reduced glucose tolerance in the ADCY8 knock-down mice on an HFD was accompanied by a reduction in plasma insulin. While the general role of the VMH in nutrient homeostasis has long been recognised, its role in the regulation of insulin secretion is less well documented [5]. Pharmacological interference with glucokinase or reduction in the expression of insulin receptors at this site reduces the secretory response of islets to a peripheral hyperglycaemic stimulus $[45,46]$. Our observations identify a third molecular actor and suggest that certain neurons in the $\mathrm{VMH}$ require $\mathrm{ADCY} 8$ for them to sense glucose, similar to the situation occurring in beta cells.

In conclusion, $\mathrm{ADCY} 8$ is required for the cellular effects of glucose and for nutrient homeostasis via the regulation of insulin secretion in mice at the level of beta cells and at the hypothalamus. Downregulation of the enzyme by prolonged 
elevated glucose levels [6] could contribute to dysfunction in diabetes. In addition, ADCY8 may present a target of endoplasmic reticulum stress, a cellular hallmark of type 2 diabetes, via the transmembrane protein wolframin (WFS1). In fact, endoplasmic reticulum stress leads to deficient activation of ADCY 8 by wolframin and results in a reduction in glucoseinduced insulin secretion at least in clonal INS-1 beta cells [47]. Finally, in view of the known neuropsychiatric phenotypes in men and mice $[48,49]$, one may ask whether ADCY8 contributes to the known link between mood disorders and diabetes [50].

Acknowledgements We thank G. Drutel and T. Leste-Lasserre (Inserm U862, Université de Bordeaux) for help with quantitative PCR and M. Bennassy, A. Milochau, C. Blatche (UMR CNRS 5248, Université de Bordeaux) and A. Lacombe (Université Paris-Diderot) for their perfect technical assistance. We gratefully acknowledge the help of the Genomic and Sequencing Facility of Bordeaux. We are grateful to E. Bezard (Institut des maladies neurodégénératives, CNRS UMR 5293, Université de Bordeaux) for generously supplying us with human post-mortem brain samples.

Funding This work was supported by grants from the Société Française de Diabétologie (to MR), the European Foundation for the Study of Diabetes (EFSD, to JL, CM and MK) and the University of Bordeaux.

Duality of interest The authors declare that there is no duality of interest associated with this manuscript.

Contribution statement MR and PV designed the research, performed experiments, researched data and contributed to the discussion and writing of the manuscript. AD, JP, AP, EK and JG designed the research, performed experiments, researched data and contributed to the drafting of the article. IL designed the research and contributed to the discussion and writing of the manuscript. MJK, CM and JL designed the research, researched data and contributed to the discussion and writing of the manuscript. JL is the guarantor of this work and, as such, had full access to all the data in the study and takes responsibility for the integrity of the data and the accuracy of the data analysis. All authors have approved the final version.

\section{References}

1. Ashcroft FM, Rorsman P (2012) Diabetes mellitus and the beta cell: the last ten years. Cell 148:1160-1171

2. Dyachok O, Idevall-Hagren O, Sagetorp J et al (2008) Glucoseinduced cyclic AMP oscillations regulate pulsatile insulin secretion. Cell Metab 8:26-37

3. Kaihara KA, Dickson LM, Jacobson DA et al (2013) beta-cellspecific protein kinase A activation enhances the efficiency of glucose control by increasing acute-phase insulin secretion. Diabetes 62: $1527-1536$

4. Seino S (2012) Cell signalling in insulin secretion: the molecular targets of ATP, cAMP and sulfonylurea. Diabetologia 55:2096-2108

5. Chan O, Sherwin RS (2012) Hypothalamic regulation of glucosestimulated insulin secretion. Diabetes 61:564-565

6. Roger B, Papin J, Vacher P et al (2011) Adenylyl cyclase 8 is central to glucagon-like peptide 1 signalling and effects of chronically elevated glucose in rat and human pancreatic beta cells. Diabetologia 54: 390-402
7. Delmeire D, Flamez D, Hinke SA, Cali JJ, Pipeleers D, Schuit F (2003) Type VIII adenylyl cyclase in rat beta cells: coincidence signal detector/generator for glucose and GLP-1. Diabetologia 46:1383-1393

8. Halls ML, Cooper DM (2011) Regulation by $\mathrm{Ca}^{2+}$-signaling pathways of adenylyl cyclases. Cold Spring Harb Perspect Biol 3:a004143

9. Hu B, Nakata H, Gu C, de Beer T, Cooper DM (2002) A critical interplay between $\mathrm{Ca}^{2+}$ inhibition and activation by $\mathrm{Mg}^{2+}$ of AC5 revealed by mutants and chimeric constructs. J Biol Chem 277:33139-33147

10. Katsushika S, Chen L, Kawabe J et al (1992) Cloning and characterization of a sixth adenylyl cyclase isoform: types $\mathrm{V}$ and VI constitute a subgroup within the mammalian adenylyl cyclase family. Proc Natl Acad Sci U S A 89:8774-8778

11. Liu Z, Yan SF, Walker JR et al (2007) Study of gene function based on spatial co-expression in a high-resolution mouse brain atlas. BMC Syst Biol 1:19

12. Kose H, Bando Y, Izumi K, Yamada T, Matsumoto K (2007) Epistasis between hyperglycemic QTLs revealed in a double congenic of the OLETF rat. Mamm Genome 18:609-615

13. Su Z, S-w T, Szatkiewicz J, Shen Y, Paigen B (2008) Candidate genes for plasma triglyceride, FFA, and glucose revealed from an intercross between inbred mouse strains NZB/B1NJ and NZW/ LacJ. J Lipid Res 49:1500-1510

14. Takeshita S, Moritani M, Kunika K, Inoue H, Itakura M (2006) Diabetic modifier QTLs identified in F2 intercrosses between Akita and A/J mice. Mamm Genome 17:927-940

15. Muglia LM, Schaefer ML, Vogt SK, Gurtner G, Imamura A, Muglia LJ (1999) The 5'-flanking region of the mouse adenylyl cyclase type VIII gene imparts tissue-specific expression in transgenic mice. J Neurosci 19:2051-2058

16. Reed SE, Staley EM, Mayginnes JP, Pintel DJ, Tullis GE (2006) Transfection of mammalian cells using linear polyethylenimine is a simple and effective means of producing recombinant adenoassociated virus vectors. J Virol Methods 138:85-98

17. Zolotukhin S (2005) Production of recombinant adeno-associated virus vectors. Hum Gene Ther 16:551-557

18. Schaefer ML, Wong ST, Wozniak DF et al (2000) Altered stressinduced anxiety in adenylyl cyclase type VIII-deficient mice. J Neurosci 20:4809-4820

19. Lamy CM, Sanno H, Labouebe G et al (2014) Hypoglycemiaactivated GLUT2 neurons of the nucleus tractus solitarius stimulate vagal activity and glucagon secretion. Cell Metab 19:527-538

20. Karaca M, Castel J, Tourrel-Cuzin C et al (2009) Exploring functional beta-cell heterogeneity in vivo using PSA-NCAM as a specific marker. PLoS ONE 4:e5555

21. Raoux M, Bornat Y, Quotb A, Catargi B, Renaud S, Lang J (2012) Non-invasive long-term and real-time analysis of endocrine cells on micro-electrode arrays. J Physiol 590:1085-1091

22. Nguyen QV, Caro A, Raoux M et al (2013) A novel bioelectronic glucose sensor to process distinct electrical activities of pancreatic beta-cells. Conf Proc IEEE Engl Med Biol Soc 2013:172-175

23. Hohmeier HE, Mulder H, Chen G, Henkel-Rieger R, Prentki M, Newgard CB (2000) Isolation of INS-1-derived cell lines with robust ATP-sensitive $\mathrm{K}^{+}$channel-dependent and -independent glucose-stimulated insulin secretion. Diabetes 49:424-430

24. Acin-Perez R, Salazar E, Kamenetsky M, Buck J, Levin LR, Manfredi G (2009) Cyclic AMP produced inside mitochondria regulates oxidative phosphorylation. Cell Metab 9:265-276

25. Levin BE, Magnan C, Dunn-Meynell A, Le Foll C (2011) Metabolic sensing and the brain: who, what, where, and how? Endocrinology 152:2552-2557

26. Leech CA, Castonguay MA, Habener JF (1999) Expression of adenylyl cyclase subtypes in pancreatic beta-cells. Biochem Biophys Res Commun 254:703-706 
27. Eizirik DL, Sammeth M, Bouckenooghe T et al (2012) The human pancreatic islet transcriptome: expression of candidate genes for type 1 diabetes and the impact of pro-inflammatory cytokines. PLoS Genet 8:e1002552

28. Hodson DJ, Mitchell RK, Marselli L et al (2014) ADCY5 couples glucose to insulin secretion in human islets. Diabetes 63:3009-3021

29. Tian G, Sol ER, Xu Y, Shuai H, Tengholm A (2014) Impaired cAMP generation contributes to defective glucose-stimulated insulin secretion after long-term exposure to palmitate. Diabetes. doi:10.2337/ db14-1036

30. Ludwig MG, Seuwen K (2002) Characterization of the human adenylyl cyclase gene family: cDNA, gene structure, and tissue distribution of the nine isoforms. J Recept Signal Transduct Res 22:79-110

31. Charles MA, Lawecki J, Pictet R, Grodsky GM (1975) Insulin secretion. Interrelationships of glucose, cyclic adenosine 3:5monophosphate, and calcium. J Biol Chem 250:6134-6140

32. Persaud SJ, Jones PM, Howell SL (1990) Glucose-stimulated insulin secretion is not dependent on activation of protein kinase A. Biochem Biophys Res Commun 173:833-839

33. Dou $\mathrm{H}$, Wang $\mathrm{C}$, Wu X, et al. Calcium influx activates adenylyl cyclase 8 for sustained insulin secretion in rat pancreatic beta cells. Diabetologia doi 10.1007/s00125-014-3437-z

34. Chepurny OG, Kelley GG, Dzhura I et al (2009) PKA-dependent potentiation of glucose-stimulated insulin secretion by Epac activator 8-pCPT-2'-O-Me-cAMP-AM in human islets of Langerhans. Am J Physiol Endocrinol Metab 298:E622-E633

35. Kitaguchi T, Oya M, Wada Y, Tsuboi T, Miyawaki A (2013) Extracellular calcium influx activates adenylate cyclase 1 and potentiates insulin secretion in MIN6 cells. Biochem J 450:365-373

36. Defer N, Marinx O, Stengel D et al (1994) Molecular cloning of the human type VIII adenylyl cyclase. FEBS Lett 351:109-113

37. Kang G, Chepurny OG, Malester B et al (2006) cAMP sensor Epac as a determinant of ATP-sensitive potassium channel activity in human pancreatic beta cells and rat INS-1 cells. J Physiol 573:595-609

38. Light PE, Manning Fox JE, Riedel MJ, Wheeler MB (2002) Glucagon-like peptide-1 inhibits pancreatic ATP-sensitive potassium channels via a protein kinase A- and ADP-dependent mechanism. Mol Endocrinol 16:2135-2144
39. Willoughby D, Everett KL, Halls ML et al (2012) Direct binding between Orail and AC8 mediates dynamic interplay between $\mathrm{Ca}^{2+}$ and cAMP signaling. Sci Signal 5:ra29

40. Tian G, Tepikin AV, Tengholm A, Gylfe E (2012) cAMP induces stromal interaction molecule 1 (STIM1) puncta but neither Orail protein clustering nor store-operated $\mathrm{Ca}^{2+}$ entry (SOCE) in islet cells. J Biol Chem 287:9862-9872

41. Zippin JH, Chen Y, Straub SG et al (2013) CO2/HCO3-and calciumregulated soluble adenylyl cyclase as a physiological ATP sensor. J Biol Chem 288:33283-33291

42. Conti AC, Maas JW Jr, Muglia LM et al (2007) Distinct regional and subcellular localization of adenylyl cyclases type 1 and 8 in mouse brain. Neuroscience 146:713-729

43. Moulder KL, Jiang X, Chang $\mathrm{C}$ et al (2008) A specific role for $\mathrm{Ca}^{2+}$. dependent adenylyl cyclases in recovery from adaptive presynaptic silencing. J Neurosci 28:5159-5168

44. Vonholdt BM, Pollinger JP, Lohmueller KE et al (2010) Genomewide SNP and haplotype analyses reveal a rich history underlying dog domestication. Nature 464:898-902

45. Osundiji MA, Lam DD, Shaw J et al (2012) Brain glucose sensors play a significant role in the regulation of pancreatic glucosestimulated insulin secretion. Diabetes 61:321-328

46. Paranjape SA, Chan O, Zhu W et al (2011) Chronic reduction of insulin receptors in the ventromedial hypothalamus produces glucose intolerance and islet dysfunction in the absence of weight gain. Am J Physiol Endocrinol Metab 301:E978-E983

47. Fonseca SG, Urano F, Weir GC, Gromada J, Burcin M (2012) Wolfram syndrome 1 and adenylyl cyclase 8 interact at the plasma membrane to regulate insulin production and secretion. Nat Cell Biol $14: 1105-1112$

48. de Mooij-van Malsen AJ, van Lith HA, Oppelaar H et al (2009) Interspecies trait genetics reveals association of Adcy8 with mouse avoidance behavior and a human mood disorder. Biol Psychiatry 66:1123-1130

49. McDonald ML, MacMullen C, Liu DJ, Leal SM, Davis RL (2012) Genetic association of cyclic AMP signaling genes with bipolar disorder. Transl Psychiatry 2:e169

50. Calkin CV, Gardner DM, Ransom T, Alda M (2013) The relationship between bipolar disorder and type 2 diabetes: more than just comorbid disorders. Ann Med 45:171-181 